\title{
Antagonism of the acute hemodynamic effects of captopril in decompensated congestive heart failure by aspirin administration
}

P.R. Viecili', D. Pamplona ${ }^{2}$, M. Park ${ }^{2}$, S.R. Silva ${ }^{3}$, J.A.F. Ramires ${ }^{4}$ and P.L. Da Luz ${ }^{1}$
Correspondence

P.L. da Luz

Unidade de Aterosclerose

InCor, FM, USP

Av. Enéas C. Aguiar, 44

05403-900 São Paulo, SP

Brasil

Fax: +55-11-3069-5447

E-mail: daluzp@incor.usp.br or

vieciliprn@uol.com.br

Research supported by FAPESP (No. 203-3/1995) and Fundação Zerbini.

Received July 5, 2002 Accepted January 8, 2003

\author{
Unidades de ${ }^{1}$ Aterosclerose and ${ }^{2}$ Emergência, \\ ${ }^{3}$ Laboratório de Farmacologia e Terapia, and \\ ${ }^{4}$ Departamento de Cardiologia, Instituto do Coração, \\ Faculdade de Medicina, Universidade de São Paulo, \\ São Paulo, SP, Brasil
}

\begin{abstract}
The concomitant use of angiotensin-converting enzyme inhibitors and aspirin may cause pharmacological antagonism. Hence we examined the effect of aspirin on the neurohormonal function and hemodynamic response to captopril in heart failure patients. Between April 1999 and August 2000, 40 patients were randomized into four equal groups: 1) captopril, 2) aspirin, 3) captopril-aspirin: captopril was given alone on the first day, followed by aspirin on the remaining days, and 4) aspirincaptopril: aspirin was given alone on the first day, followed by captopril on the remaining days. Hemodynamic, norepinephrine and prostaglandin measurements were performed pre- and post-medication for 4 days. Captopril (50 mg) was given orally every $8 \mathrm{~h}$ and 300 $\mathrm{mg}$ aspirin was given on the first day, and $100 \mathrm{mg} /$ day thereafter. In the captopril group and only on the first day of captopril-aspirin, captopril produced increases in cardiac index $\left(2.1 \pm 0.6\right.$ to $2.5 \pm 0.51 \mathrm{~min}^{-1} \mathrm{~m}^{-2}$, $\mathrm{P}<0.0001)$, and reduced peripheral vascular resistance $(1980 \pm 580$ to $1545 \pm 506$ dyn s$\left.^{-1} \mathrm{~cm}^{-5} / \mathrm{m}^{2}, \mathrm{P}<0.0001\right)$ and pulmonary wedge pressure ( $20 \pm 4$ to $15 \pm 4 \mathrm{mmHg}, \mathrm{P}<0.0001$ ). In contrast, aspirin alone or associated with captopril showed no significant hemodynamic changes. Norepinephrine decreased $(\mathrm{P}<0.02)$ only in the captopril group. Prostaglandin levels did not differ significantly among groups. Thus, aspirin compromises the short-term hemodynamic and neurohormonal effects of captopril in patients with acute decompensated heart failure.
\end{abstract}

Key words

- Pharmacological antagonism

- Aspirin

- Angiotensin-converting enzyme inhibitors

- Decompensated heart failure

- Hemodynamics and neurohormonal changes

\section{Introduction}

Angiotensin-converting enzyme (ACE) inhibitors are used extensively for the treatment of congestive heart failure. Several studies have documented their ability to reduce global and cardiovascular mortality, reinfarction, and needs for rehospitalization following acute myocardial infarction $(1,2)$. Aspirin (ASA) on the other hand, is also routinely used for the prevention of thrombotic events in patients with coronary artery disease (3). Thus, simultaneous therapy with both drugs is frequently recommended for 
patients with ventricular dysfunction and coronary artery disease.

More recently, concern has been raised with respect to a potential antagonism between these two drugs (4). For instance, in the Consensus II study which included 6090 post-acute myocardial infarction patients, Nguyen et al. (5) found, in a retrospective analysis, that the effect of enalapril was less favorable among patients taking ASA at baseline than in those not taking it. On the other hand, Hall et al. (6) also reported that a single dose of ASA (325 mg) blunted the acute hemodynamic effect of enalaprilat in patients with severe heart failure.

The exact mechanism involved in this interaction is not completely understood. The vasodilatory effects of ACE inhibitors are attributed to inhibition of angiotensin II synthesis as well potentiation of bradykinin (BK)-induced vasodilation (7). Prostaglandin $(\mathrm{PG})$ production is also stimulated by $\mathrm{BK}$, and hence may contribute to vasodilatation. ASA, on the other hand, being a cyclooxygenase inhibitor (8), could reduce, PG production at least in part and therefore diminish or eliminate its vasodilatory effect (9).

The issue is of considerable clinical importance, given the large number of patients with acute myocardial infarction and heart failure of ischemic origin who are potential candidates for both therapies (10). We determined whether or not a low ASA dose would interfere with the hemodynamic and neurohormonal effects of captopril in decompensated heart failure.

\section{Material and Methods}

\section{Study patients}

Forty consecutive patients with decompensated chronic congestive heart failure, functional classes III/IV (New York Heart Association), were studied over a period of six days in the Cardiovascular Intensive Care Unit. Patients with right-sided, acute, dia- stolic, high-output, congenital and valvular heart failure were excluded. Patients with specific conditions that produce or exacerbate heart failure, such as infections, severe arrhythmias, pulmonary emboli, or significant pulmonary, renal, hepatic, hematological diseases and exposure to ASA or other nonsteroidal anti-inflammatory drugs for $\leq 15$ days were also excluded. Informed consent was obtained from all subjects. The study was approved by the Scientific Committee of the Heart Institute (InCor), São Paulo, SP, Brazil.

\section{Hemodynamic measurements}

A Swan-Ganz catheter was inserted through the subclavian vein for cardiac output measurement. Heart rate and mean arterial pressure were recorded by automatic non-invasive pressure monitoring with the Hewlett-Packard OmniCare Component Monitoring System; right atrial pressure and pulmonary and capillary wedge pressure were recorded through the Swan-Ganz catheter. Cardiac output (CO) was determined in triplicate by the thermodilution technique. The following parameters were derived according to the formulas indicated: cardiac index $\left(1 \mathrm{~min}^{-1} \mathrm{~m}^{-2}\right)=\mathrm{CO} /$ body surface area; systemic vascular resistance $\left(\right.$ dyn s-1 $\left.\mathrm{cm}^{-5} / \mathrm{m}^{2}\right)=$ mean arterial pressure $\mathrm{x} 80 / \mathrm{CO}$, and pulmonary vascular resistance $\left(\right.$ dyn $\left.\mathrm{s}^{-1} \mathrm{~cm}^{-5}\right)=$ mean pulmonary capillary wedge pressure $\mathrm{x}$ 80/CO.

\section{Neurohormonal analysis}

All blood samples were collected from the Swan-Ganz catheter, except on the first day when the antecubital vein was used, and were taken with the patients at rest. For measurements of prostaglandin $\mathrm{E}_{2}\left(\mathrm{PGE}_{2}\right)$ and prostacyclin $\mathrm{I}_{2}\left(\mathrm{PGI}_{2}\right)$ (measured as 6keto-prostaglandin $\mathrm{F}_{1 \alpha}$ [6-keto-PGF $\left.\mathrm{P}_{1 \alpha}\right]$, the stable breakdown product of $\mathrm{PGI}_{2}$ ) in plasma, $5 \mathrm{ml}$ of blood was drawn into frozen tubes 
with a mixture of EDTA and indomethacin, in the early morning at rest and every $8 \mathrm{~h}$ thereafter. Blood samples were centrifuged immediately at $2000 \mathrm{~g}$ for $15 \mathrm{~min}$ at $4^{\circ} \mathrm{C}$ and the supernatants were removed, frozen, and stored at $-80^{\circ} \mathrm{C}$ until the time for assay. $\mathrm{PGE}_{2}$ and $\mathrm{PGI}_{2}$ were measured by the $\mathrm{PGE}_{2}\left[{ }^{125} \mathrm{I}\right]-$ RIA kit and 6-keto-PGF ${ }_{1 \alpha}\left[{ }^{125} \mathrm{I}\right]-$ RIA kit (NENTM, Life Science Products, Boston, MA, USA). Norepinephrine (NE) was sampled once a day, in the early morning at rest, in ice with EGTA as anticoagulant and glutathione solutions, and the samples were immediately centrifuged at $2000 \mathrm{~g}$ for $20 \mathrm{~min}$ at $4^{\circ} \mathrm{C}$. The supernatants were removed, frozen, and stored at $-20^{\circ} \mathrm{C}$ until assay by an electrochemical detection method after purification by HPLC.

\section{Study protocol}

The study was carried out in two phases: the compensation phase, when patients were stabilized clinically, and the study phase, when hemodynamic measurements and neurohormonal analyses were performed over a period of 4 days. In the compensation phase, all patients received a standardized diet with fluid and salt restriction and fixed intravenous doses of lanatoside $\mathrm{C}$, furosemide and nitroprusside for about $48 \mathrm{~h}$ without any ACE inhibitors until clinical stabilization or until they felt confortable in the recumbent position. During the study, no vasoactive or anti-inflammatory drugs were given. Complete blood cell count and plasma glucose, creatinine, urea, sodium and potassium were measured on alternate days, by standard techniques. A Swan-Ganz catheter was inserted in the evening of the last day of the compensation phase. Sodium nitroprusside was interrupted $2 \mathrm{~h}$ before the study phase. Additional medications such as furosemide, 40 $\mathrm{mg} i v$ twice a day and digoxin, $0.25 \mathrm{mg}$ a day, were given orally.

In the morning of the third day of hospitalization, at 7:00 h, patients were random- ized into four groups of ten patients receiving the following medications: 1) captopril group: captopril was given orally at a daily dose of $50 \mathrm{mg}$ three times a day for 4 days; 2 ) ASA group: ASA was given orally at a dose of $300 \mathrm{mg}$ a day on the first day, and $100 \mathrm{mg}$ on the subsequent three days; 3) captopril plus ASA group (Cap-ASA): captopril was given orally at a daily dose of $50 \mathrm{mg}$ twice a day for 4 days in combination with $300 \mathrm{mg}$ ASA on the second day, and $100 \mathrm{mg}$ a day on the last 2 days; 4) ASA plus captopril group (ASA-Cap): ASA was given orally at a dose of $300 \mathrm{mg}$ a day on the first day, and $100 \mathrm{mg}$ on the subsequent 3 days, in combination with captopril at a daily dose of $50 \mathrm{mg}$ twice a day on the last two days. Captopril and ASA were administered orally during fasting, and together in the ASA-Cap or CapASA groups. Hemodynamic measurements were performed at baseline and $1 \mathrm{~h}$ after captopril or ASA.

\section{Statistical analysis}

The groups were compared in terms of clinical, laboratory, echocardiographic, hemodynamic and neurohormonal variables. The chi-square test for categorical variables and the Student $t$-test for continuous variables were used. Differences between serial measurements were assessed by repeatedmeasures ANOVA and the Newman-Keuls multiple comparison test. Values are reported as mean $\pm \mathrm{SD}$ and $\mathrm{P}<0.05$ was considered to be statistically significant.

\section{Results}

\section{Patient characteristics}

The study was conducted on 24 men and 16 women with a mean age of $62 \pm 13$ years. All patients had been symptomatic for at least 1 year. Heart failure was due to hypertensive heart disease in most of them. Sinus rhythm was present in 34 patients $(85 \%)$ and 
chronic atrial fibrillation in $6(15 \%)$. Enlarged cardiac silhouette, prominent pulmonary vasculature in the upper lung zones, alveolar edema and pleural effusions were the most common signs in the chest radiograph. The echocardiographic mean left ventricular ejection fraction was $40 \pm 4.5 \%$. Patients were comparable in the four groups. Additional demographic characteristics, labo- ratory and echocardiographic findings are shown in Tables 1 and 2.

\section{Clinical response}

All patients were compensated within $48 \mathrm{~h}$ by the intravenous drug regimen. The daily dose of $150 \mathrm{mg}$ captopril was well tolerated by most of them. Systolic arterial pressure lower

Table 1. Demographic characteristics of patients with stabilized heart failure.

\begin{tabular}{|c|c|c|c|c|}
\hline & Captopril & Aspirin & Cap-ASA & ASA-Cap \\
\hline Age (mean \pm SD) & $66 \pm 12$ & $60 \pm 13$ & $66 \pm 10$ & $63 \pm 13$ \\
\hline Sex, men & 6 & 5 & 5 & 6 \\
\hline \multicolumn{5}{|l|}{ Clinical history } \\
\hline Hypertension & 9 & 9 & 7 & 9 \\
\hline CAD & 3 & 1 & 3 & 3 \\
\hline Current smoker & 1 & 2 & 2 & 3 \\
\hline Diabetes mellitus & 2 & 2 & 4 & 3 \\
\hline \multicolumn{5}{|l|}{ Etiology } \\
\hline Hypertensive disease & 7 & 7 & 5 & 7 \\
\hline Ischemic heart disease & 3 & 1 & 3 & 3 \\
\hline Dilated cardiomyopathy & 1 & 3 & 2 & 1 \\
\hline \multicolumn{5}{|l|}{ NYHA functional class } \\
\hline Class III & 2 & 3 & 4 & 4 \\
\hline Class IV & 8 & 7 & 6 & 6 \\
\hline \multicolumn{5}{|l|}{ Previous medication } \\
\hline Diuretics & 8 & 7 & 9 & 9 \\
\hline ACE inhibitors & 9 & 7 & 8 & 8 \\
\hline Digoxin & 9 & 8 & 9 & 9 \\
\hline
\end{tabular}

CAD: coronary artery disease; NYHA: New York Heart Association; Cap-ASA: captopril plus aspirin group; ASA-Cap: aspirin plus captopril group; ACE: angiotensin-converting enzyme. There were no statistical differences among groups ( $N=10$ in each one) for any of the characteristics (repeated-measures ANOVA).

Table 2. Laboratory and echocardiographic findings

\begin{tabular}{lcccr}
\hline & Captopril & Cap-ASA & Aspirin & ASA-Cap \\
\hline Laboratory & & & & \\
$\quad$ Creatinine (mg/dl) & $1.4 \pm 0.4$ & $1.4 \pm 0.8$ & $1.6 \pm 0.9$ & $1.6 \pm 0.6$ \\
$\quad$ Urea (mg/dl) & $61.0 \pm 31.0$ & $56.0 \pm 41.0$ & $66.0 \pm 30.0$ & $67.0 \pm 26.0$ \\
$\quad$ Norepinephrine (ng/dl) & $1463.0 \pm 1200.0$ & $1075.0 \pm 651.0$ & $1220.0 \pm 817.0$ & $820.0 \pm 401.0$ \\
Echocardiographic & & & & \\
$\quad$ Ejection fraction (\%) & $36.0 \pm 3.0$ & $43.0 \pm 4.0$ & $42.0 \pm 5.0$ & $37.0 \pm 3.0$ \\
\hline
\end{tabular}

Data are reported as mean \pm SD for 10 patients per group. Cap-ASA: captopril plus aspirin group; ASA-Cap: aspirin plus captopril group. Norepinephrine levels were obtained at baseline on the first day of the compensation phase. There were no statistically significant differences among groups for any of the parameters reported in the table (repeated-measures ANOVA). 
Table 3. Hemodynamic parameters.

\begin{tabular}{|c|c|c|c|c|c|c|c|c|}
\hline & \multicolumn{2}{|c|}{ 1st day } & \multicolumn{2}{|c|}{ 2nd day } & \multicolumn{2}{|c|}{ 3rd day } & \multicolumn{2}{|c|}{ 4th day } \\
\hline & Pre & Post & Pre & Post & Pre & Post & Pre & Post \\
\hline \multicolumn{9}{|l|}{$\mathrm{HR}(\mathrm{bpm})$} \\
\hline Captopril & $83 \pm 13$ & $82 \pm 12$ & $80 \pm 14$ & $81 \pm 14$ & $81 \pm 13$ & $83 \pm 13$ & $79 \pm 13$ & $79 \pm 12$ \\
\hline ASA & $85 \pm 11$ & $85 \pm 10$ & $84 \pm 13$ & $87 \pm 10$ & $82 \pm 11$ & $84 \pm 12$ & $82 \pm 12$ & $85 \pm 15$ \\
\hline Cap-ASA & $96 \pm 22$ & $91 \pm 19$ & $91 \pm 14$ & $91 \pm 12$ & $89 \pm 8$ & $88 \pm 9$ & $89 \pm 10$ & $90 \pm 11$ \\
\hline ASA-Cap & $86 \pm 13$ & $87 \pm 14$ & $86 \pm 14$ & $86 \pm 14$ & $89 \pm 17$ & $84 \pm 15$ & $89 \pm 15$ & $85 \pm 14$ \\
\hline \multicolumn{9}{|l|}{ MAP (mmHg) } \\
\hline Captopril & $93 \pm 20$ & $89 \pm 23$ & $91 \pm 21$ & $89 \pm 20$ & $91 \pm 20$ & $85 \pm 15$ & $83 \pm 19$ & $85 \pm 23$ \\
\hline ASA & $92 \pm 17$ & $93 \pm 19$ & $88 \pm 14$ & $95 \pm 13$ & $92 \pm 13$ & $89 \pm 15$ & $94 \pm 10$ & $90 \pm 21$ \\
\hline Cap-ASA & $90 \pm 14$ & $89 \pm 13$ & $90 \pm 12$ & $87 \pm 12$ & $90 \pm 13$ & $86 \pm 11$ & $92 \pm 11$ & $84 \pm 13$ \\
\hline ASA-Cap & $106 \pm 15$ & $106 \pm 16$ & $105 \pm 21$ & $103 \pm 19$ & $103 \pm 17$ & $96 \pm 21$ & $101 \pm 20$ & $102 \pm 18$ \\
\hline \multicolumn{9}{|c|}{$\mathrm{Cl}\left(I \mathrm{~min}^{-1} \mathrm{~m}^{-2}\right)$} \\
\hline Captopril ${ }^{\#}$ & $2.1 \pm 0.5$ & $2.5 \pm 0.6^{* *}$ & $2.0 \pm 0.6$ & $2.5 \pm 0.7^{* *}$ & $1.8 \pm 0.5$ & $2.3 \pm 0.6^{* *}$ & $2.0 \pm 0.7$ & $2.3 \pm 0.7^{* *}$ \\
\hline ASA & $2.0 \pm 0.5$ & $1.9 \pm 0.5$ & $2.0 \pm 0.5$ & $2.0 \pm 0.5$ & $1.9 \pm 0.5$ & $1.8 \pm 0.4$ & $2.2 \pm 0.4$ & $2.1 \pm 0.4$ \\
\hline Cap-ASA & $1.7 \pm 0.6$ & $2.2 \pm 0.7^{* *}$ & $1.8 \pm 0.4$ & $1.8 \pm 0.4$ & $1.8 \pm 0.5$ & $2.0 \pm 0.6$ & $2.0 \pm 0.5$ & $2.0 \pm 0.5$ \\
\hline ASA-Cap & $1.8 \pm 0.5$ & $1.9 \pm 0.6$ & $2.0 \pm 0.3$ & $1.8 \pm 0.3$ & $2.0 \pm 0.2$ & $2.0 \pm 0.3$ & $1.9 \pm 0.3$ & $2.0 \pm 0.5$ \\
\hline \multicolumn{9}{|c|}{ SVR (dyn s $\mathrm{s}^{-1} \mathrm{~cm}^{-5} / \mathrm{m}^{2}$ ) } \\
\hline Captopril ${ }^{+}$ & $1980 \pm 580$ & $1545 \pm 506^{* *}$ & $2157 \pm 895$ & $1684 \pm 582 * *$ & $2285 \pm 791$ & $1668 \pm 574^{* *}$ & $1839 \pm 501$ & $1686 \pm 572 * *$ \\
\hline ASA & $2071 \pm 558$ & $2231 \pm 517$ & $2096 \pm 599$ & $2321 \pm 607$ & $2279 \pm 563$ & $2260 \pm 446$ & $1994 \pm 453$ & $2101 \pm 564$ \\
\hline Cap-ASA & $2369 \pm 830$ & $1846 \pm 542^{* *}$ & $2267 \pm 558$ & $2226 \pm 595$ & $2320 \pm 825$ & $2040 \pm 701$ & $2110 \pm 680$ & $1880 \pm 590$ \\
\hline ASA-Cap & $2486 \pm 892$ & $2485 \pm 1126$ & $2130 \pm 612$ & $2278 \pm 575$ & $2062 \pm 536$ & $1952 \pm 656$ & $2149 \pm 573$ & $2202 \pm 637$ \\
\hline \multicolumn{9}{|c|}{ MPAP (mmHg) } \\
\hline Captopril & $34 \pm 6$ & $34 \pm 7$ & $31 \pm 6$ & $28 \pm 8$ & $28 \pm 9$ & $28 \pm 8$ & $28 \pm 7$ & $27 \pm 7$ \\
\hline ASA & $38 \pm 7$ & $36 \pm 8$ & $36 \pm 8$ & $35 \pm 9$ & $35 \pm 10$ & $33 \pm 8$ & $34 \pm 7$ & $35 \pm 8$ \\
\hline Cap-ASA & $41 \pm 11$ & $38 \pm 10$ & $37 \pm 6$ & $36 \pm 7$ & $37 \pm 9$ & $37 \pm 7$ & $38 \pm 4$ & $38 \pm 7$ \\
\hline ASA-Cap & $45 \pm 13$ & $44 \pm 13$ & $44 \pm 14$ & $43 \pm 14$ & $44 \pm 14$ & $40 \pm 14$ & $43 \pm 13$ & $41 \pm 13$ \\
\hline \multicolumn{9}{|c|}{ MRAP (mmHg) } \\
\hline Captopril & $9 \pm 6$ & $8 \pm 4$ & $7 \pm 5$ & $7 \pm 5$ & $7 \pm 4$ & $7 \pm 5$ & $7 \pm 4$ & $7 \pm 4$ \\
\hline ASA & $8 \pm 3$ & $7 \pm 4$ & $6 \pm 4$ & $5 \pm 3$ & $6 \pm 4$ & $6 \pm 5$ & $6 \pm 4$ & $6 \pm 4$ \\
\hline Cap-ASA & $11 \pm 6$ & $9 \pm 5$ & $9 \pm 4$ & $9 \pm 4$ & $10 \pm 6$ & $10 \pm 5$ & $10 \pm 4$ & $10 \pm 4$ \\
\hline ASA-Cap & $10 \pm 5$ & $10 \pm 5$ & $10 \pm 7$ & $10 \pm 7$ & $9 \pm 6$ & $9 \pm 7$ & $9 \pm 7$ & $9 \pm 7$ \\
\hline \multicolumn{9}{|c|}{ PCWP (mmHg) } \\
\hline Captopril* & $20 \pm 5$ & $15 \pm 5^{* *}$ & $19 \pm 6$ & $15 \pm 6^{* *}$ & $20 \pm 8$ & $16 \pm 6^{* *}$ & $19 \pm 7$ & $15 \pm 6^{* *}$ \\
\hline ASA & $21 \pm 6$ & $21 \pm 6$ & $20 \pm 5$ & $20 \pm 6$ & $20 \pm 6$ & $21 \pm 5$ & $21 \pm 6$ & $21 \pm 6$ \\
\hline Cap-ASA & $19 \pm 6$ & $17 \pm 5^{* *}$ & $21 \pm 6$ & $19 \pm 5$ & $20 \pm 4$ & $19 \pm 5$ & $21 \pm 4$ & $21 \pm 5$ \\
\hline ASA-Cap & $24 \pm 6$ & $24 \pm 6$ & $24 \pm 6$ & $23 \pm 8$ & $23 \pm 6$ & $20 \pm 5$ & $22 \pm 7$ & $21 \pm 8$ \\
\hline
\end{tabular}

Values are reported as means \pm SD for pre- and post-medication of four groups ( $N=10$ per group). HR, heart rate; MAP, mean arterial pressure; $\mathrm{Cl}$, cardiac index; SVR, systemic vascular resistance; MPAP, mean pulmonary arterial pressure; MRAP, mean right atrial pressure; PCWP, pulmonary capillary wedge pressure.

${ }^{*} \mathrm{P}<0.04$ vs ASA, Cap-ASA, and ASA-Cap groups. ${ }^{\#} \mathrm{P}<0.002$ vs ASA, Cap-ASA, and ASA-Cap groups. ${ }^{+} \mathrm{P}<0.009$ vs ASA, Cap-ASA, and ASA-Cap groups. ${ }^{*} P<0.0001$ vs pre-medication data. 
Figure 1. Changes in cardiac in$\operatorname{dex}(\mathrm{Cl})$ before (open bar) and 1 $\mathrm{h}$ after (filled bar) administration of captopril (Cap), aspirin (ASA) or both. $\mathrm{Cl}$ increased significantly in the captopril group (A) and on the first day of treatment in the Cap-ASA group (B) $(P<0.0001$, repeated-measures ANOVA). Introduction of aspirin in the Cap-ASA group on the second day prevented further increases in $\mathrm{Cl}$. The $\mathrm{Cl}$ remained unchanged in the ASA (C) and ASA-Cap groups (D). than $100 \mathrm{mmHg}$ occurred in one patient and was treated with intravenous saline. Only one patient showed a $30 \%$ increase in creatinine levels on the last day of study and was not excluded. Diuretic dosage was adjusted in 5 patients, but no other adjustments in medication were necessary. No cases of embolization, bleeding, cardiac arrhythmias or pneumothorax were observed. No patient died during the study.
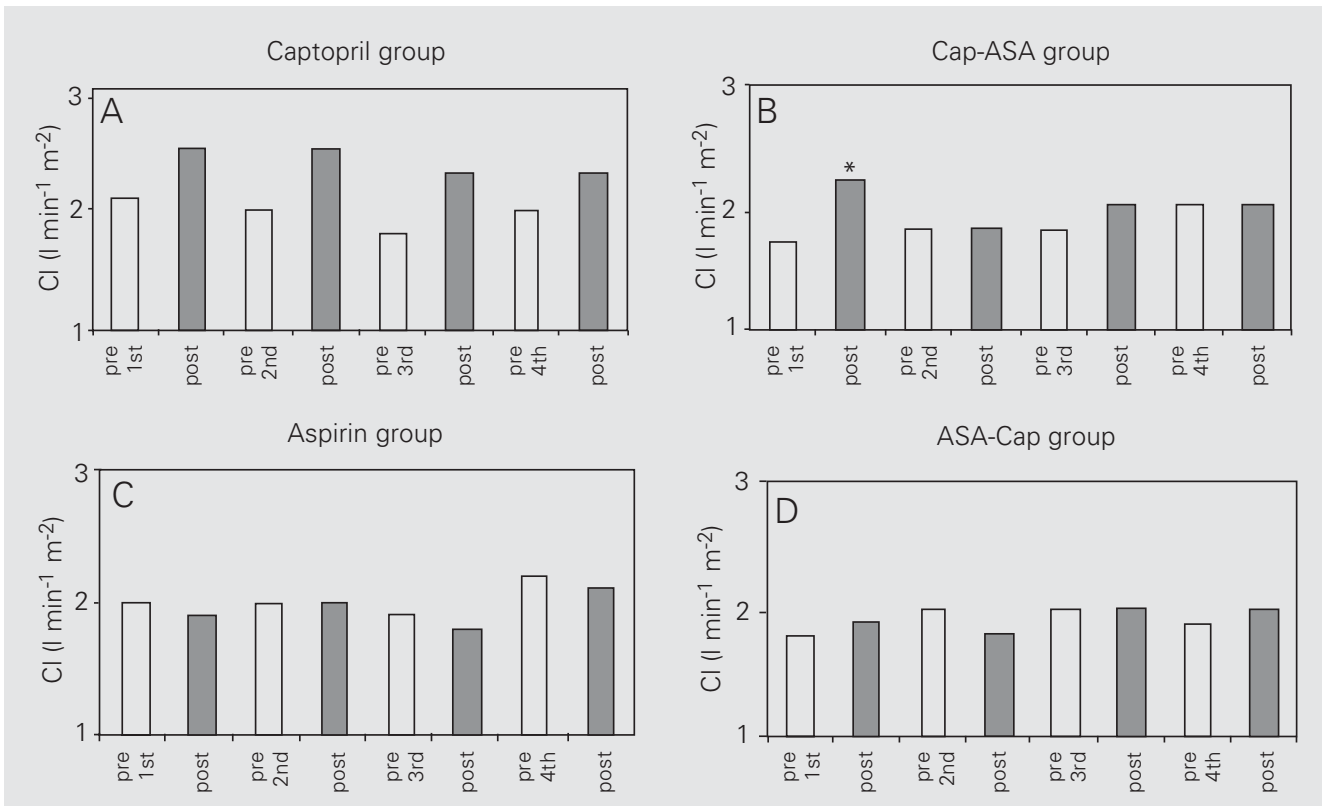

Figure 2. Changes in systemic vascular resistance (SVR) before (open bar) and $1 \mathrm{~h}$ after (filled bar) administration of captopril (Cap), aspirin (ASA) or both. SVR decreased significantly in the captopril group (A) and on the first day of treatment in the CapASA group (B) $(P<0.0001$, repeated-measures ANOVA), but increased with the introduction of aspirin on the second day in this group. SVR remained unchanged in the ASA $(C)$ and ASACap groups (D).
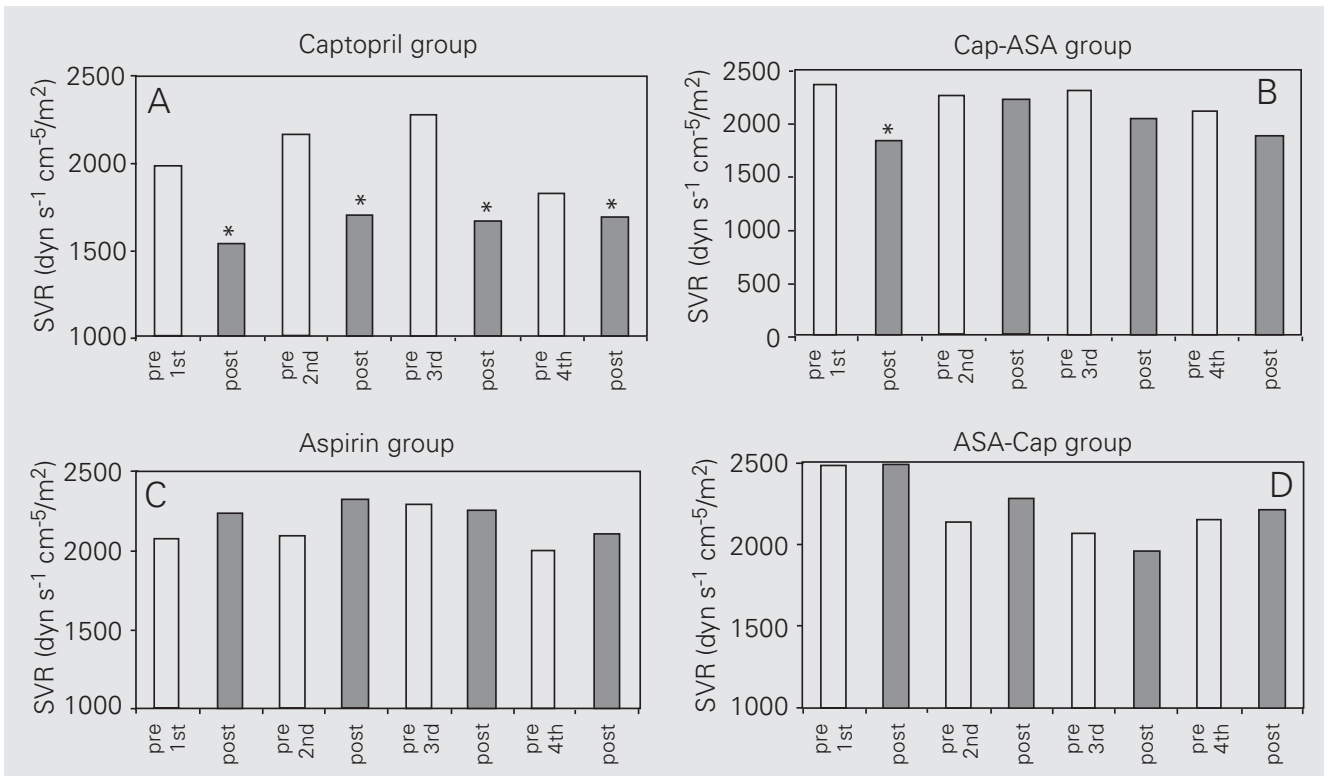
captopril reduced peripheral vascular resistance by $26 \%(1980 \pm 580$ to $1545 \pm 506 \mathrm{dyn}$ $\left.\mathrm{s}^{-1} \mathrm{~cm}^{-5} / \mathrm{m}^{2}, \mathrm{P}<0.0001\right)$, and pulmonary wedge pressure by $28 \%$ ( $20 \pm 4$ to $15 \pm 4 \mathrm{mmHg}$, $\mathrm{P}<0.0001$ ) (Figures $2 \mathrm{~A}$ and $3 \mathrm{~A}$ ). There were no significant changes in heart rate, mean arterial, mean right atrial or mean pulmonary arterial pressure.

In contrast, ASA alone did not induce significant changes in cardiac index, peripheral vascular resistance or pulmonary wedge pressure (Figures 1C, 2C and 3C) or in heart rate, mean arterial, mean right atrial and mean pulmonary arterial pressures. On the other hand, patients who received captopril followed by ASA exhibited a dual response pattern: on the first day, the expected response to captopril was observed, namely, significant increases in cardiac index and reductions in peripheral vascular resistance and pulmonary wedge pressure, but no changes in heart rate, mean arterial, mean right atrial or mean pulmonary arterial pressure. However, when ASA was added the hemodynamic effect of captopril was completely abolished (Figures 1B, 2B and 3B).

Conversely, patients who received ASA first followed by captopril showed no initial hemodynamic alterations, just as in the pure
ASA group. Differently from the captopril group, when captopril was added, no hemodynamic responses were noted, thus indicating that previous ASA administration blocked the action of captopril (Figures 1D, 2D and 3D).

\section{Neurohormonal effects}

Mean NE values on the day of admission are shown in Table 2 and confirm the presence of a severe degree of cardiac decompensation when patients were hospitalized. After clinical stabilization, NE levels decreased significantly $(\mathrm{P}<0.006)$ compared to initial levels in all patients. During the study phase, patients in the captopril group showed a significant decrease in NE levels (533 \pm 233 to $408 \pm 235 \mathrm{ng} / \mathrm{dl} ; \Delta 30 \%$; $\mathrm{P}<0.02)$; on the other hand, in the ASA, ASA-Cap and Cap-ASA groups NE levels were unchanged, although in the ASA group a trend towards an increase $(620 \pm 250$ to $806 \pm 595 \mathrm{ng} / \mathrm{dl}$; $\Delta 23 \%$; $\mathrm{P}<0.07)$ was noted. The percent variation of NE levels is illustrated in Figure 4.

The means of the three daily measurements of $\mathrm{PGE}_{2}$ and $\mathrm{PGI}_{2}$ (6-keto-PGF $\mathrm{PG}_{1 \alpha}$ ) were $245 \pm 82$ and $231 \pm 79 \mathrm{ng} / \mathrm{dl}$ for the captopril group, $270 \pm 150$ and $265 \pm 146 \mathrm{ng} / \mathrm{dl}$ for the
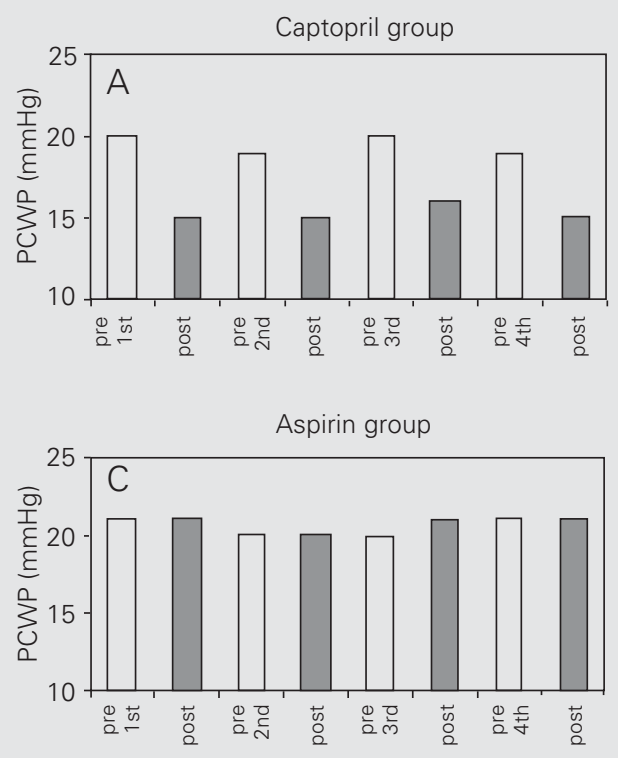

Cap-ASA group

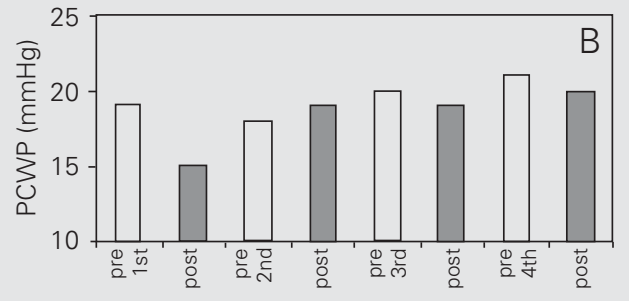

ASA-Cap group

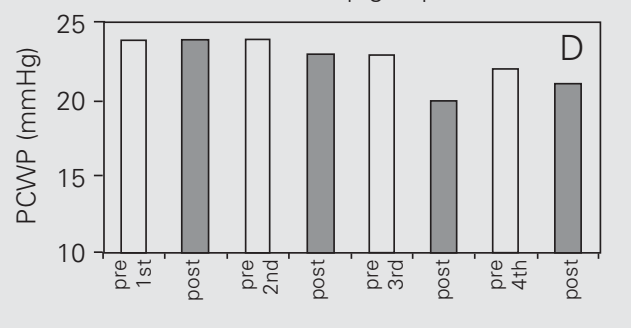

Figure 3. Changes in pulmonary capillary wedge pressure (PCWP) before (open bar) and $1 \mathrm{~h}$ after (closed bar) administration of captopril (Cap), aspirin (ASA) or both. PCWP was reduced significantly in the captopril group (A) and on the first day in the Cap-ASA group (B); this effect was abolished in the Cap-ASA group with introduction of aspirin. PCWP remained unchanged in the aspirin group (C). In the ASA-Cap group (D) no significant differences were noted with the addition of captopril. 
Figure 4. Norepinephrine (NE) levels compared with mean levels on the first day of the study. Data are reported as means for 10 patients in each group. Blood for NE was collected before drug administration. There was a significant reduction $(P<0.02$, repeated-measures ANOVA) in NE levels in the captopril group that persisted throughout the study period. There was a trend towards an increase in the aspirin group $(P<0.07$, repeated-measures ANOVA); NE levels remained unchanged in the CapASA (captopril plus aspirin) and ASA-Cap (aspirin plus captopril) groups.

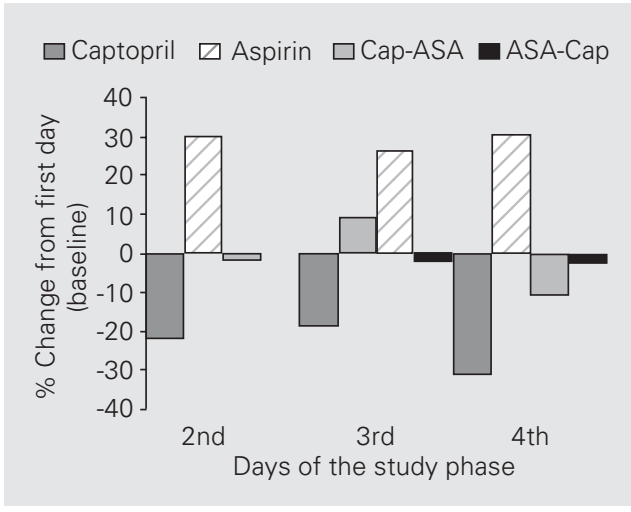

ASA group, $232 \pm 96$ and $263 \pm 104 \mathrm{ng} / \mathrm{dl}$ for the Cap-ASA group, and $176 \pm 87$ and $212 \pm$ $88 \mathrm{ng} / \mathrm{dl}$ for the ASA-Cap group, respectively. There was no statistically significant difference among the groups during the study.

\section{Discussion}

In this study we demonstrate an antagonism between acute ASA and captopril administration in patients with advanced stable heart failure. Thus, while captopril alone produced an increase in cardiac index and a decrease in systemic vascular resistance and pulmonary capillary wedge pressure, its combination with ASA completely eliminated these effects. ASA by itself did not cause any measurable hemodynamic effects. In addition, captopril reduced plasma NE levels, an effect that was not observed with ASA or with the combination of captopril and ASA. ASA antagonism was evident from the initial dose. In contrast, in patients already using ASA, the addition of captopril did not cause any variations in hemodynamic profile.

This is the first invasive hemodynamic study that used low doses of ASA. We used $300 \mathrm{mg}$ ASA on the first day, which is sufficient to block cyclo-oxygenase within less than $24 \mathrm{~h}(1,3)$; this dose was followed by $100 \mathrm{mg} /$ day, and this interaction persisted throughout the 4 days of the study. Thus, low doses of ASA had an antagonistic effect similar to that of higher doses used by other researchers $(6,11)$.

The mechanisms responsible for this interaction are not entirely clear, but interference with one or more components of the renin-angiotensin system is probably involved. ACE leads to formation of angiotensin II, but also inactivates BK because it also is kininase II, which degrades BK (7). BK has potent vasodilatory effects that can be attributed to two endothelium-related mechanisms: a direct effect and an indirect one due to the release of additional mediators, such as $\mathrm{PG}$ and nitric oxide. BK induces PG liberation by means of phospholipase A activation (7). Thus, arachidonic acid released from membrane phospholipids is converted, by cyclo-oxygenase, into $\mathrm{PG}\left(\mathrm{PGD}_{2}\right.$, $\left.\mathrm{PGE}_{2}, \mathrm{PGF}\right), \mathrm{PGI}_{2}$ and thromboxane $\mathrm{A}_{2}$. $\mathrm{PGI}_{2}$, specifically, is also a potent vasodilator (7) and may thus contribute to the vasodilatory effect of ACE inhibitors. Consequently, ACE inhibitors decrease vasoconstriction due to reduced angiotensin II synthesis, and indirectly produce vasodilatation through the increase of BK, nitric oxide and PG (7). On the other hand, the negative interaction of ASA/ACE inhibitors can be explained by the blockade of cyclo-oxygenase by ASA (4). It is therefore suggested that ASA inhibits $\mathrm{PGI}_{2}$ synthesis to an extent sufficient to compromise the hemodynamic effects of captopril.

Several human studies have examined this pharmacological antagonism, but the results are conflicting. While six studies have suggested a negative interaction (6,11-15), six others did not find it $(13,16-20)$ and still another (21) showed a positive interaction. Differences in hemodynamic methods, ASA doses, ACE inhibitor doses and types as well as in patient populations may account for these discrepancies. For instance, non-invasive hemodynamic methods were used in the six studies that did not show interaction $(13,16-20)$. All studies except three $(13,18$, 20) evaluated heart failure class II, III patients; in comparison, our patients had more advanced heart failure. Hence, our data not 
only confirmed the antagonism, even with a very low ASA dose of $100 \mathrm{mg} /$ day, but might suggest that invasive hemodynamic methods are more sensitive than non-invasive ones in detecting hemodynamic changes resulting from interaction between ASA and ACE inhibitors.

\section{Prostaglandin analysis}

Prostaglandin analysis did not reveal antagonism with captopril in agreement with previous observations (4). Of the aforementioned studies, only three measured PG (1618) and none found consistent variations. The absence of PG variations may be attributed to technical and/or methodological problems (22). Evidence suggests that PG have distinct behaviors in different biological systems: thus, blood from the microcirculation is more sensitive than blood from the systemic circulation (23). Our blood samples were taken from the main pulmonary artery and might not have represented peripheral endothelium PG levels.

\section{Norepinephrine levels}

The high initial plasma NE levels indicated the severity of heart failure. As observed after a 48-h compensatory period, there was an important reduction of initial levels followed by clinical stabilization. As shown in Figure 4, a persistent and significant reduction of these levels occurred only in the captopril group. In contrast, patients of the ASA group showed a trend to increased NE levels, which did not reach statistical significance. In this case, standard treatment with digitalis, diuretics and water restriction was not sufficient to blunt this trend. This behavior may have been enhanced by ASA, i.e., via cyclo-oxygenase blockade of $\mathrm{PGI}_{2}$ and its vasodilatory effects. No changes were observed when using ASA and captopril simultaneously. However, since ASA was the only drug added to conventional treatment, it may have been responsible for the lack of reduction of NE levels, although a control group treated only by conventional therapy was not available.

Our data agree partly with those reported by Hall et al. (6), who observed a $20 \%$ drop in NE levels in patients taking enalapril, with or without ASA. The study by Baur et al. (17) did not show any changes, regardless of the drugs used.

\section{Long-term interaction}

Because of the short duration of our study, the results cannot be extrapolated to longterm treatment observations. In this respect, a careful analysis of studies such AIRE, ISIS-4, SOLVD, Consensus II as well as a recent meta-analysis indicates that this issue remains unresolved (5,23-26).

\section{Implications}

A recent survey of over 200,000 postmyocardial infarction patients showed that only $45 \%$ of those with important ventricular ischemic dysfunction took ACE inhibitors but $76 \%$ used ASA (10). Thus, ACE inhibitors are clearly underused. This fact could have implications in the morbidity and mortality rate in acute myocardial infarction complicated by ventricular dysfunction, since we would not know if the increased use of ACE inhibitors would interfere with survival because most patients would be using both drugs.

\section{Limitations of the study}

It should be emphasized that the present study focused on acute effects; therefore, long-term results cannot be extrapolated from these data. Secondly, most patients were hypertensive and although the renin-angiotensin system and neurohormonal adaptation depend more on severity of heart failure than etiology, this fact should be considered. Third, the number of patients was somewhat 
small. However, the consistency of the data suggests that the findings are reliable.

The results of the present study clearly showed that acute administration of low ASA doses compromised the acute hemodynamic and neurohormonal effects of captopril on decompensated heart failure, mainly of hypertensive etiology. These observations deserve consideration in the management of acute decompensated heart failure.

\section{References}

1. Ray SG, Pye M, Oldroyd KG, Christie J, Connelly DT, Northridge DB, Ford I, Morton JJ, Dargie HJ \& Cobbe SM (1993). Early treatment with captopril after acute myocardial infarction. British Heart Journal, 69: 215-222.

2. Braunwald E (1991) (Editorial). ACE Inhibitors. A cornerstone of the treatment of heart failure. New England Journal of Medicine, 325: 351-353.

3. Hennkens CH, Dyken ML \& Fuster V (1997). Aspirin as a therapeutic agent in cardiovascular disease. A statement for healthcare professionals from the American Heart Association. Circulation, 96: 27512753.

4. Teerlink JR \& Massie BM (1999). The interaction of ACE inhibitors and aspirin in heart failure: torn between two lovers. American Heart Journal, 138: 194-197.

5. Nguyen KN, Aursnes I \& Kjekshus J (1997). Interaction between enalapril and aspirin on mortality after acute myocardial infarction: Subgroup analysis of the Cooperative New Scandinavian Enalapril Survival Study II (CONSENSUS II). American Journal of Cardiology, 79: 115-119.

6. Hall D, Zeitler H \& Rudolph W (1992). Counteraction of the vasodilator effects of enalapril by aspirin in severe heart failure. Journal of the American College of Cardiology, 20: 1549-1555.

7. Schrör K (1990). Converting enzyme inhibitors and the interaction between kinins and eicosanoids. Journal of Cardiovascular Pharmacology, 15 (Suppl 6): S60-S68.

8. Patrono C (1994). Aspirin as an antiplatelet drug. New England Journal of Medicine, 330: 1287-1294.

9. Burch J, Stanford N \& Majerus P (1978). Inhibition of platelet prostaglandin synthetase by oral aspirin. Journal of Clinical Investigation, 61: 314-319.

10. Barron H, Michaels AD, Maynard C \& Every N (1998). Use of angiotensin-converting enzyme inhibitors at discharge in patients with acute myocardial infarction in the United States: Data from the National Registry of Myocardial Infarction 2. Journal of the American College of Cardiology, 32: 360-367.

11. Spaulding $C$, Charbonnier B, Cohen-Solal A, Jullière $Y$, Kromer E \& Benhamamda K (1998). Acute hemodynamic interaction of aspirin and ticlodipina with enalapril: results of a double-blind, randomized comparative trial. Circulation, 98: 757-765.

12. Nakamura M, Funakoshi T, Arakawa N, Yoshida H, Makita S \& Hiramori K (1994). Effect of angiotensin-converting enzyme inhibitors on endothelium-dependent peripheral vasodilatation in patients with chronic heart failure. Journal of the American College of Cardiology, 24: 1321-1327.

13. Guazzi CJ, Celeste F, Guazzi M, Santambrogio G, Rossi M \& Trabatoni D (1998). Antihypertensive efficacy of angiotensin converting enzyme inhibition and aspirin counteraction. Clinical Pharmacology and Therapeutics, 63: 79-86.

14. Guazzi M, Marenzi G, Alimento M, Contini M \& Agostini P (1997). Improvement of alveolar-capillary membrane diffusing capacity with enalapril in chronic heart failure and counteracting effect of aspirin.
Circulation, 95: 1930-1936

15. Guazzi PG, Pontane G \& Agostini P (1999). Aspirin worsens exercise performance and pulmonary gas exchange in patients with heart failure who are taking angiotensin-converting enzyme inhibitors. American Heart Journal, 138: 254-260.

16. Von Wijngaarden J, Smit AJ, De Graeff PA, Van Gilst WH, Van der Broek AS \& Van Veldhuisen DJ (1994). Effects of acetylsalicylic acid on peripheral hemodynamics in patients with chronic heart failure treated with angiotensin-converting enzyme inhibitors. Journal of Cardiovascular Pharmacology, 23: 240-245.

17. Baur LH, Schipperheyn JJ, Van Der Larse A et al. (1995). Combining salicylate and enalapril in patients with coronary artery disease and heart failure. British Heart Journal, 73: 227-236.

18. Boger R, Bode-Boger S, Kramme P, Tsikas D, Gutzki FM \& Frölich JC (1996). Effect of captopril on prostacyclin and nitric oxide formation in healthy human subjects: interaction with low dose acetylsalicylic acid. British Journal of Clinical Pharmacology, 42: 721-727.

19. Katz S, Radin M, Graves T, Hauck C, Block A \& Le Jemtel T (1999). The Ifetroban Study Group: Effect of aspirin and ifetroban on skeletal muscle blood flow in patients with congestive heart failure treated with enalapril. Journal of the American College of Cardiology, 34: 170-176

20. Oosterga M, Anthonio RL, Kam PJ, Kingma H \& Crijns HJ (1998). Effects of aspirin on angiotensin-converting enzyme inhibition and left ventricular dilatation one year after acute myocardial infarction. American Journal of Cardiology, 81: 1178-1181.

21. Jeserich M, Pape L, Just H, Hornig B, Kupfer M, Münzel T, Lohmann A, Olschewski M \& Drexler H (1995). Effect of long-term angiotensin-converting enzyme inhibition on vascular function in patients with chronic congestive heart failure. American Journal of Cardiology, 76: 1079-1082.

22. Kyrle PA, Eicheler $H$, Jäger A \& Lechner K (1987). Inhibition of prostacyclin and thromboxane A2 generation by low-dose aspirin at the site of plug formation in man in vivo. Circulation, 5: 1025-1029.

23. Al-Khada A, Salem D, Rand W, Udelson J, Smith J \& Konstan M (1998). Antiplatelet agents and survival: A cohort analysis from the Studies of Left Ventricular Dysfunction (SOLVD) Trial. Journal of the American College of Cardiology, 31: 419-425.

24. Hall D (2000). The halve and halve not. Editorial Comment. Journal of the American College of Cardiology, 35: 1808-1812.

25. Leor J, Reicher-Reis H, Goldbourd U, Boyko V, Gottlib S, Battler A \& Behar S (1999). Aspirin and mortality in patients treated with angiotensin-converting enzyme inhibitors. A cohort study of 11,575 patients with coronary artery disease. Journal of the American College of Cardiology, 33: 1920-1925.

26. Latini R, Tognoni G, Maggioni AP et al. (2000). Clinical effects of early angiotensin-converting enzyme inhibitor treatment for acute myocardial infarction are similar in the presence and absence of aspirin: systematic overview of individual data from 96,000 randomized patients. Journal of the American College of Cardiology, 35: 1801-1807. 